University of New Hampshire

University of New Hampshire Scholars' Repository

Jackson Estuarine Laboratory

Institute for the Study of Earth, Oceans, and

Space (EOS)

6-1974

\title{
MODE:IGPP Measurements of Bottom Pressure and Temperature
}

\author{
Frank Snodgrass
}

Wendell Brown

Walter Munk

Follow this and additional works at: https://scholars.unh.edu/jel

\section{Comments}

This is an article published by American Meteorological Society in Journal of Physical Oceanography in 1975, available online: https://doi.org/10.1175/1520-0485(1975)005<0063:MMOBPA>2.0.C0;2

\section{Recommended Citation}

Snodgrass, F., W. Brown and W. Munk. 1975. MODE: IGPP measurements of bottom pressure and temperature. Journal of Physical Oceanography 5:63-74

This Article is brought to you for free and open access by the Institute for the Study of Earth, Oceans, and Space (EOS) at University of New Hampshire Scholars' Repository. It has been accepted for inclusion in Jackson Estuarine Laboratory by an authorized administrator of University of New Hampshire Scholars' Repository. For more information, please contact Scholarly.Communication@unh.edu. 


\title{
MODE : IGPP Measurements of Bottom Pressure and Temperature ${ }^{1}$
}

\author{
Frank Snodgrass, Wendell Brown and Walter Munk \\ Institute of Geophysics and Planetary Physics, Scripps Institution of Oceanography, University of California, La Jolla 92037
}

(Manuscript received 17 June 1974, in revised form 5 July 1974)

\begin{abstract}
We review the MODE deployment of IGPP bottom instruments, together with preliminary tests on the Pacific seafloor and in the laboratory. Pressure and temperature were measured with quartz-crystal transducers in different configurations. Spectra of instrument noise in the laboratory and on the seafloor were estimated from duplicate transducers. These estimates are prerequisite to the forthcoming discussions of MODE tides, the bottom experiment, and internal waves. There are two puzzling features: (i) the temperature noise continuum on the seafloor is generally $20 \mathrm{~dB}$ above that in the laboratory, and (ii) the pressure noise spectrum has a tidal line structure. Instrument drifts during MODE are of the order of a few millibars and a millidegree Celcius, respectively.
\end{abstract}

\section{Introduction}

Over the last five years there has been an effort at the Institute of Geophysics and Planetary Physics (IGPP) of measuring pressure and temperature on the deep seafloor. It has been found convenient to use quartz crystals for both these two basic measurements (in different configurations), mounted on a capsule that was freely dropped, and subsequently recalled by acoustic command from a surface vessel (Snodgrass, 1968). Most of the effort was directed toward deep-sea tides, and drops of roughly one-month duration have become somewhat routine.

The $\mathrm{MODE}^{2}$ bottom experiment offered an opportunity to extend our effort toward much lower than tidal frequencies, and drops of longer duration. Previously measured pressure noise spectra (Caldwell et al., 1969; Irish and Snodgrass, 1972), when extrapolated into lower frequencies, indicated that the detection of the expected MODE signals of a few millibars at cycle-permonth frequencies was a marginal undertaking. For that reason some laboratory and field tests were conducted prior to the MODE deployment (Table 1), but these did not remove the uncertainty. Accordingly, we employed dual sensors in MODE for in situ noise estimates, at the expense of a broader station coverage. As it has turned out, we did unequivacally measure pressure fluctuations, but the success was not so much the result of a reduced sensor noise relative to earlier estimates, than of a higher signal amplitude than had been anticipated.

Prior to MODE we had become interested in the statistics of internal waves. There was particular need

\footnotetext{
1 MODE Contribution No. 14.

2 Mid-Ocean Dynamics Experiment.
}

for coherence measurements at great depth. Consequently, we combined measurements of bottom pressure and temperature with measurements of deep midwater temperatures, using multiple sensors on a cable extending $1 \mathrm{~km}$ upward from the seafloor installation.

\section{Pre-MODE measurements}

\section{a. JOSIE well test}

Installation of the sensors in a thermally stable well in the basement of IGPP avoided difficulties of longterm sea tests. The four sensors, thermally connected by an aluminum block (Fig. 1), were placed at the center of a $0.5 \mathrm{~m}^{3}$ box filled with sand, then lowered into $3 \mathrm{~m}$ of seepage water at the bottom of the $25 \mathrm{~m}$ well (Fig. 2). The ports of the pressure sensors were open to ambient pressure, but protected from plugging by sand with a light covering of cotton. Lead-acid batteries provided power to prevent contamination of the test with spurious $110 \mathrm{~V}$ ac line surges. Voltages applied to the sensors were individually regulated.

Four-minute averages of the sensor signals were recorded on magnetic tape. The pressure record (Fig. 3) is dominated by atmospheric effects, the temperature record by $10^{-3 \circ} \mathrm{C}$ fluctuations superimposed on a $10^{-2{ }^{\circ}} \mathrm{C}$ excursion over the 52-day test.

\section{b. JOSIE $175 \mathrm{SW}$}

To check equipment and test procedures in preparation for the MODE experiment, two sea tests were conducted during 1972. For the first test, $75 \mathrm{~km}$ seaward of the continental borderland off southern California 
TABLE 1. Summary of tests conducted in preparation for and during MODE for each capsule installation. 1972 was devoted primarily to test equipment and to evaluate sensors. Tests are identified by capsule names and locations (Well refers to IGPP Well). The values given in parentheses are the nominal sensor depths in meters. $P_{B}, P_{T}$ refer to pressure transducers on bottom and on top of $1 \mathrm{~km}$ cable. $T_{B}, T_{1}, T_{2}, \cdots$ refer to temperature transducers on bottom and staggered near top of cable (see Fig. 4 for typical transducer configuration).

\begin{tabular}{|c|c|c|c|c|c|c|}
\hline Test & Date & Site & \multicolumn{4}{|c|}{ Sensors } \\
\hline \multicolumn{7}{|c|}{1972 Pacific tests } \\
\hline $\begin{array}{l}\text { JOSIE } \\
\text { Well }\end{array}$ & $\begin{array}{l}14 \text { Apr } \\
5 \text { Jun }\end{array}$ & IGPP & \multicolumn{4}{|c|}{$P_{1}, P_{2}, T_{1}$ and $T_{2}(3)$ instrument noise test in well } \\
\hline $\begin{array}{l}\text { JOSIE } \\
175 \mathrm{SW}\end{array}$ & $\begin{array}{l}15 \text { Jun } \\
19 \text { Jul }\end{array}$ & $\begin{array}{r}31^{\circ} 06.3^{\prime} \mathrm{N} \\
119^{\circ} 56.0^{\prime} \mathrm{W}\end{array}$ & $\begin{array}{l}P_{T}(2682) \\
T_{2}(2700)\end{array}$ & $\begin{array}{l}P_{B}(3719) \\
T_{3}(2708)\end{array}$ & $\begin{array}{l}T_{1}(2684) \\
T_{4}(2712)\end{array}$ & $T_{\mathbf{5}}(2751)$ \\
\hline $\begin{array}{l}\text { REIKO } \\
250 \mathrm{SW}\end{array}$ & $\begin{array}{l}12 \mathrm{Nov} \\
13 \mathrm{Dec}\end{array}$ & $\begin{aligned} & 30^{\circ} 36^{\prime} \mathrm{N} \\
& 120^{\circ} 52^{\prime} \mathrm{W}\end{aligned}$ & $\begin{array}{l}P_{T}(2919) \\
T_{1}(2921)\end{array}$ & $T_{2}(2937)$ & $T_{3}(2945)$ & $T_{B}(3921)$ \\
\hline $\begin{array}{l}\text { EDIE } \\
250 \mathrm{SW}\end{array}$ & $\begin{array}{l}12 \text { Nov } \\
13 \text { Dec }\end{array}$ & $\begin{array}{r}30^{\circ} 36^{\prime} \mathrm{N} \\
120^{\circ} 52^{\prime} \mathrm{W}\end{array}$ & $\begin{array}{l}P_{T}(2915) \\
T_{1}(2917)\end{array}$ & $\begin{array}{l}P_{B}(3917) \\
T_{2}(2965)\end{array}$ & $T_{3}(2990)$ & $T_{\mathrm{s}}(3119)$ \\
\hline \multicolumn{7}{|c|}{1973 MODE installations } \\
\hline MERT & $\begin{array}{l}18 \mathrm{Mar} \\
12 \mathrm{Jul}\end{array}$ & $\begin{array}{l}27^{\circ} 59.3^{\prime} \mathrm{N} \\
69^{\circ} 40.3 \mathrm{~W}\end{array}$ & $\begin{array}{l}P_{T}(4459) \\
T_{1}(4477)\end{array}$ & $\begin{array}{l}P_{B}(5461) \\
T_{2}(4485)\end{array}$ & $T_{B}(5461)$ & \\
\hline REIKO & $\begin{array}{l}16 \text { Mar } \\
13 \text { May }\end{array}$ & $\begin{array}{l}27^{\circ} 59.2^{\prime} \mathrm{N} \\
69^{\circ} 39.1^{\prime} \mathrm{W}\end{array}$ & $\begin{array}{l}P_{T}(4428) \\
T_{3}(4503)\end{array}$ & $\begin{array}{l}T_{1}(4430) \\
T_{5}(4631)\end{array}$ & $\begin{array}{l}T_{2}(4478) \\
T_{B}(5430)\end{array}$ & \\
\hline REIKO & $\begin{array}{l}14 \mathrm{May} \\
5 \mathrm{Jul}\end{array}$ & $\begin{array}{l}27^{\circ} 58.2^{\prime} \mathrm{N} \\
69^{\circ} 40.4^{\prime} \mathrm{W}\end{array}$ & $\begin{array}{l}P_{T}(4459) \\
T_{3}(4534)\end{array}$ & $\begin{array}{l}P_{B}(5461) \\
T_{4}(4546)\end{array}$ & $\begin{array}{l}T_{1}(4461) \\
T_{5}(4662)\end{array}$ & $T_{B}(5461)$ \\
\hline EDIE & $\begin{array}{l}20 \mathrm{Mar} \\
11 \mathrm{May}\end{array}$ & $\begin{array}{l}26^{\circ} 26.9^{\prime} \mathrm{N} \\
69^{\circ} 19.0^{\prime} \mathrm{W}\end{array}$ & \multicolumn{3}{|c|}{$\begin{array}{l}P_{B 1}, P_{B 2}, T_{B 1} \text { and } T_{B 2}(5424) \\
\quad \text { All sensors on bottom }\end{array}$} & \\
\hline EDIE & $\begin{array}{l}12 \mathrm{May} \\
10 \mathrm{Jul}\end{array}$ & $\begin{array}{l}26^{\circ} 27.8^{\prime} \mathrm{N} \\
69^{\circ} 19.6^{\prime} \mathrm{W}\end{array}$ & \multicolumn{3}{|c|}{$\begin{array}{l}P_{B 1}, P_{B 2}, T_{B 1} \text { and } T_{B 2}(5421) \\
\text { All sensors on bottom }\end{array}$} & \\
\hline
\end{tabular}

Capsule JOSIE ${ }^{3}$ was fitted with a $1 \mathrm{~km}$ multi-conductor cable, held taut between the bottom anchor and the buoyant capsule (Fig. 4). Five temperature sensors were attached along the upper $200 \mathrm{~m}$ of the cable to measure internal waves. The vertical motion of the temperature sensors due to cable drag was determined from the difference, $P_{T}-P_{B}$, between pressure at the top and bottom of the cable. Temperatures were corrected for cable motion assuming a linear temperature gradient. Temperature corrections to pressure measurements were omitted as they are negligible (unlike MODE).

The data obtained during the 33-day sea test (Fig. 5) indicated highly coherent temperature signals over the $67 \mathrm{~m}$ sensor spacing. Spikes in $P_{T}$ indicate a vertical displacement of the sensor by as much as $14 \mathrm{~m}$. Bottom pressure $P_{B}$ compares well with known tides. Tidal components are prominent in the temperature records, as a" a result of being in the near field of mode conversion of surface into internal tides at the continental slope. As a consequence, the following test was moved further seaward.

\footnotetext{
${ }^{3}$ The digital recorder, previously used in the IGPP well with five sensors, was modified to accept seven input signals by recording sensors $T_{1}$ and $P_{T}$ alternately on channel 1 , and $T_{5}$ and $P_{B}$ alternately on channel 5. Data from these sensors therefore are 4-min averages at 8 -min intervals. Data from sensors $T_{2}, T_{3}$ and $T_{4}$ (recorded on individual channels) are 4 -min averages at 4-min intervals.
}

\section{c. REIKO and EDIE $250 \mathrm{SW}$}

The new test site was $180 \mathrm{~km}$ from the continental borderland (roughly $250 \mathrm{n} \mathrm{mi} \mathrm{SW}$ of San Diego). Three new capsules, REIKO, EDIE and MERT (constructed for MODE) were equipped with the 7-channel COS/ MOS recording systems. Temperature sensors were spaced along $1 \mathrm{~km}$ cables similar to JOSIE (Fig. 4).

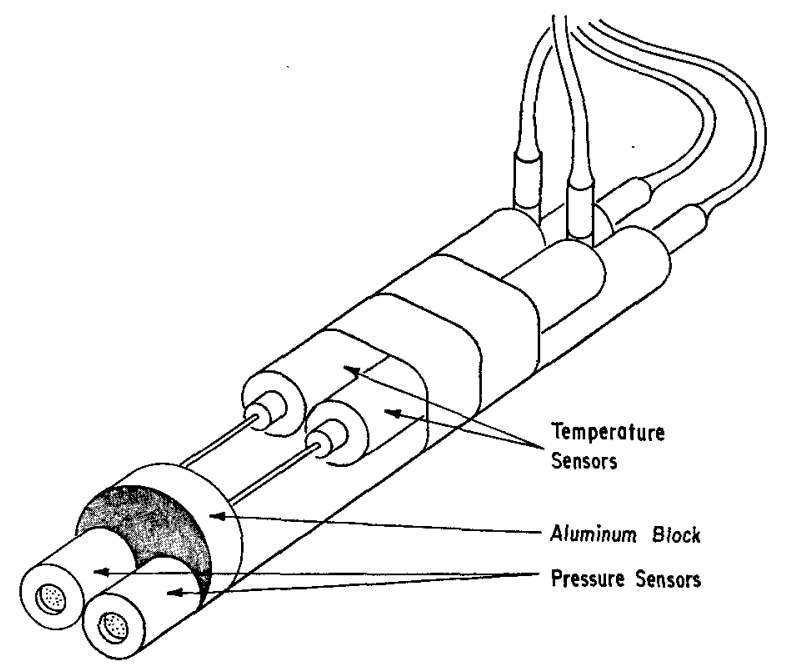

FIG. 1. Configuration of the two pressure and two temperature sensors thermally coupled by an aluminum block. 


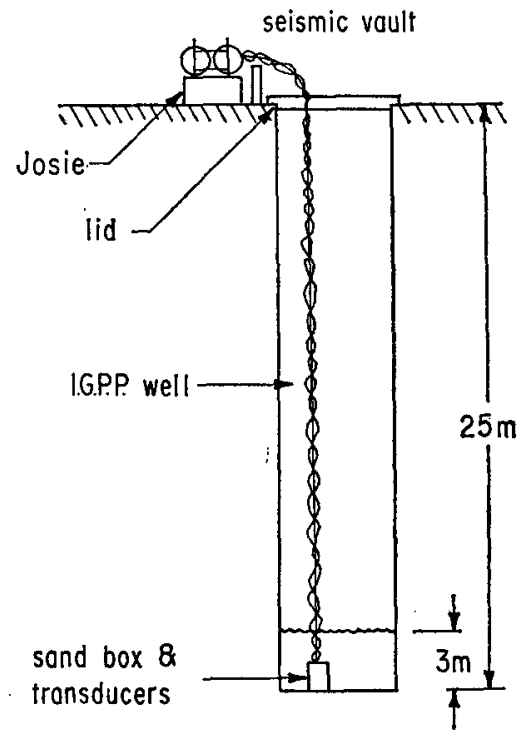

FIG. 2. Schematic diagram of the instrumental noise test performed in a concrete well in the basement of IGPP. A sandbox containing the temperature and pressure sensors (Fig. 1) was placed underwater at the bottom of the well. The measurements were recorded and stored by capsule JOSIE in the seismic vault above.

Duplicate pressure and temperature sensors on REIKO and EDIE were to give in situ sensor noise measurements on the seafloor (the duplicate instruments failed).

MERT suffered cable damage during launch in heavy seas, and could not be repaired at sea. REIKO and EDIE were installed at a $2.75 \mathrm{~km}$ separation, and data were obtained from 11 sensors (Fig. 6) that yielded some information on vertical and horizontal coherence scales. Several sensors failed, primarily due to faulty connectors.

\section{MODE measurements}

All capsules were installed in March 1973 during Cruise I of the $F . V$. Hunt, monitored and repaired in
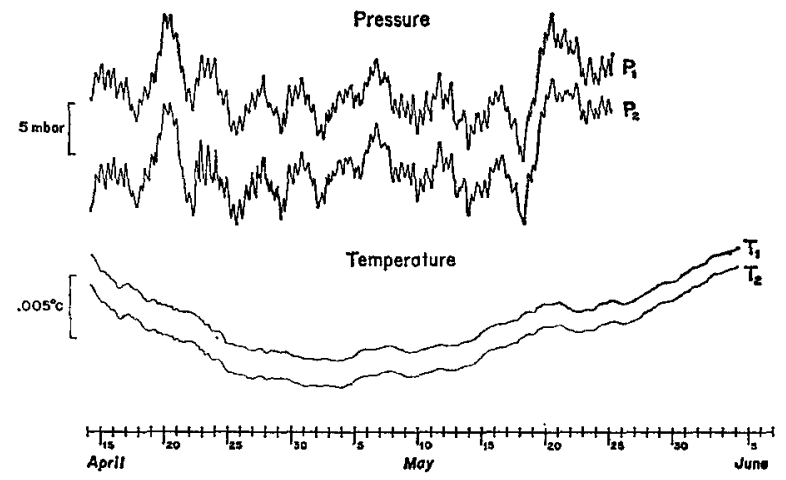

FIG. 3. Temperature records of dual sensors in the IGPP well during 1972. The plotted data are 24-min averages of the original 4 min samples. Tick marks are at Greenwich midnight.

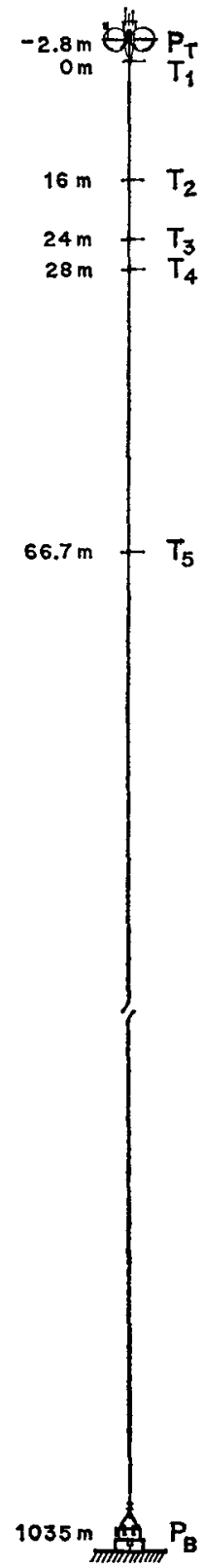

FIG. 4. A typical array (JOSIE $175 \mathrm{SW}$ ), showing sensor depths relative to $T_{1}$ (see Table 1 for other installations). Eighteen 10 -inch diameter glass spheres (not shown) were attached to the cable for buoyancy.

May during Hunt III, and recovered in July during Bunt V. A summary of the observations is shown in Fig. 7. For redundancy, REIKO and MERT were placed a few kilometers apart near the central mooring. Bottom temperature sensors on both capsules permitted pressure measurements to be corrected for the large $\left(0.05^{\circ} \mathrm{C}\right)$ Atlantic seafloor temperature fluctuations detected by Baker et al. (1973) during pre-MODE. The two capsules were fitted with $1 \mathrm{~km}$ cables carrying 

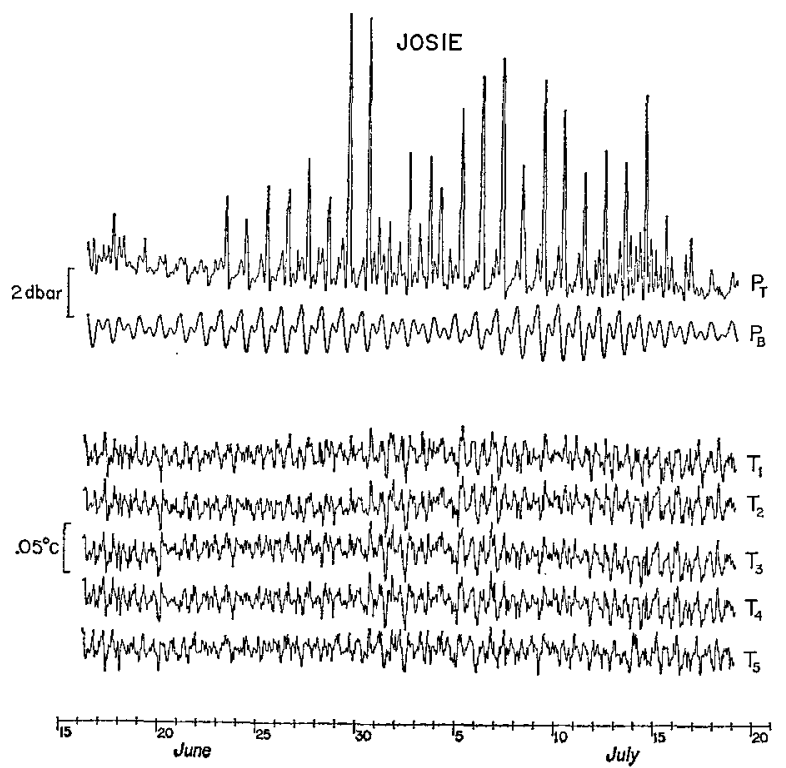

Frg. 5. Summary of 1972 pressure and temperature data at a site 175 mi southwest of San Diego, using the array in Fig. 4 (see also Table 1). The 2 dbar scale applies to both pressure records; the $0.05^{\circ} \mathrm{C}$ scale to all five temperature records. Plotted data are 4-min averages, as recorded. $P_{T}$ spikes are due to cable motion in horizontal currents. Tick marks are Greenwich midnight. The bottom pressure probe failed 29 June; after this date $P_{B}$ is calculated from previously determined deep-sea tidal coefficients.

midwater temperature sensors, as previously employed in the Pacific tests.

At the southern site, EDIE (Fig. 8) was equipped with dual pressure and temperature sensors to provide for redundancy, and in situ estimates of sensor noise.

\section{a. MERT}

Two temperature sensors failed during installation: one sensor was accidentally disconnected as the capsule was launched, the other had a connector short under high pressure. Acoustic diagnostic signals indicated that all other sensors were functioning at the time of installation. Since the midwater sensors were not considered vital to MODE, a decision was made to not risk damaging the system by recovering the capsule for repair. However, post-MODE examination indicated that the $T_{B}$ sensor was noisy until the $P_{B}$ sensor failed 1 April, and that a short in the cable termination at the anchor had been responsible for the failures in $P_{B}, P_{T}$, and the acoustical release system.

When the ship returned in May, an attempt was made to recover the capsule, but neither the release system nor the acoustical system would respond. Recovery was made in July when the capsule was released by a preset backup quartz-crystal timer.

\section{b. REIKO}

The $P_{B}$ sensor failed as it neared bottom during the launch. REIKO was left in place while other installa- tions were completed, with the intention of repairing the unit when the ship's deck was cleared of equipment, but poor weather prevented the recovery until Hunt III. Later examination indicated that $T_{2}$ had failed after 21 days, and $T_{B}$ had failed after 26 days. The $P_{B}$ and $T_{2}$ failures were due to high pressure shorts of cable connectors. The bottom pressure sensor mysteriously stopped for nine days in May.

\section{c. EDIE}

Acoustic diagnostics indicated normal functioning following launch, yet Hunt III diagnostics revealed malfunctioning in both pressure sensors. The capsule was recovered but no difficulty with the equipment could be found; lead-acid batteries (left on bottom with the anchor) were assumed defective. With new batteries the equipment operated properly during the last two months. Post-MODE examination found both pressure
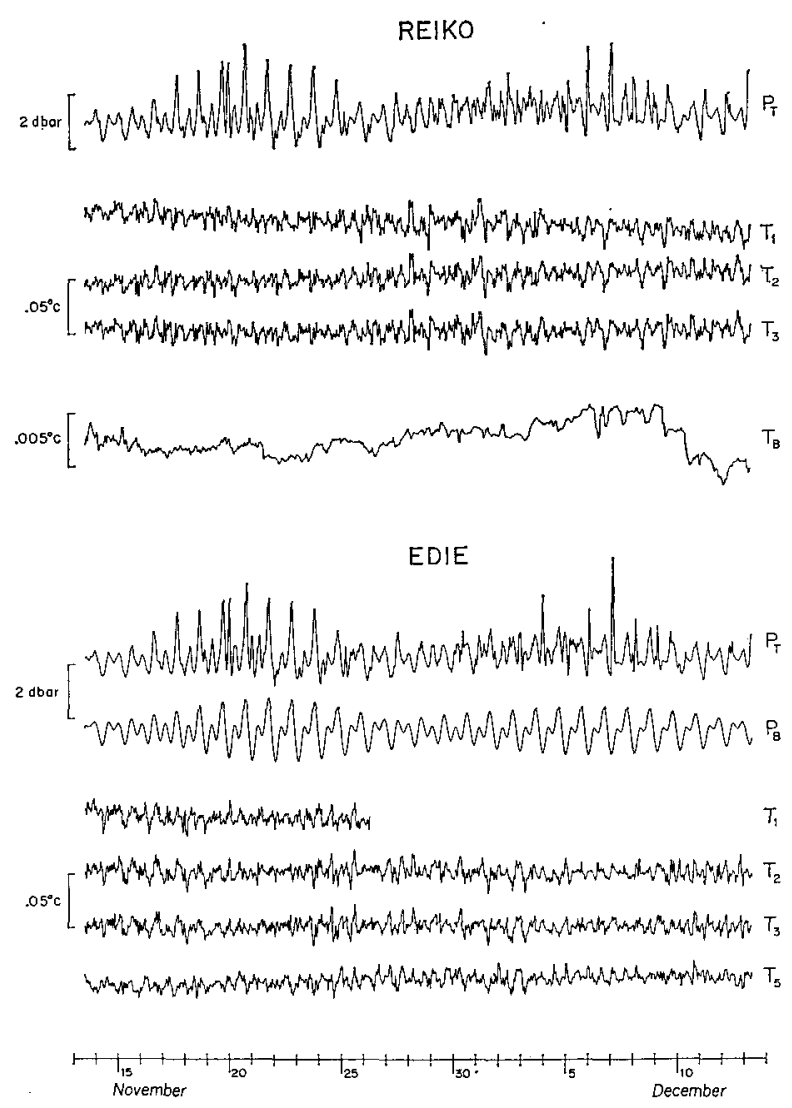

FIG. 6. Summary of 1972 pressure and temperature data at a site $250 \mathrm{mi}$ southwest of San Diego. EDIE was located $2.75 \mathrm{~km}$ $310^{\circ} \mathbf{T}$ from REIKO. Each had temperature sensors attached along a $1 \mathrm{~km}$ vertical cable, similar to the array in Fig. 4 (see Table 1). All midwater temperatures are plotted to the same scale, the bottom temperature being amplified tenfold. Plotted data are 24 min averages of the measurements at $30 \mathrm{~s}$ intervals. $P_{T}$ spikes occur nearly simultaneously at the two capsules. Tick marks are Greenwich midnight. 

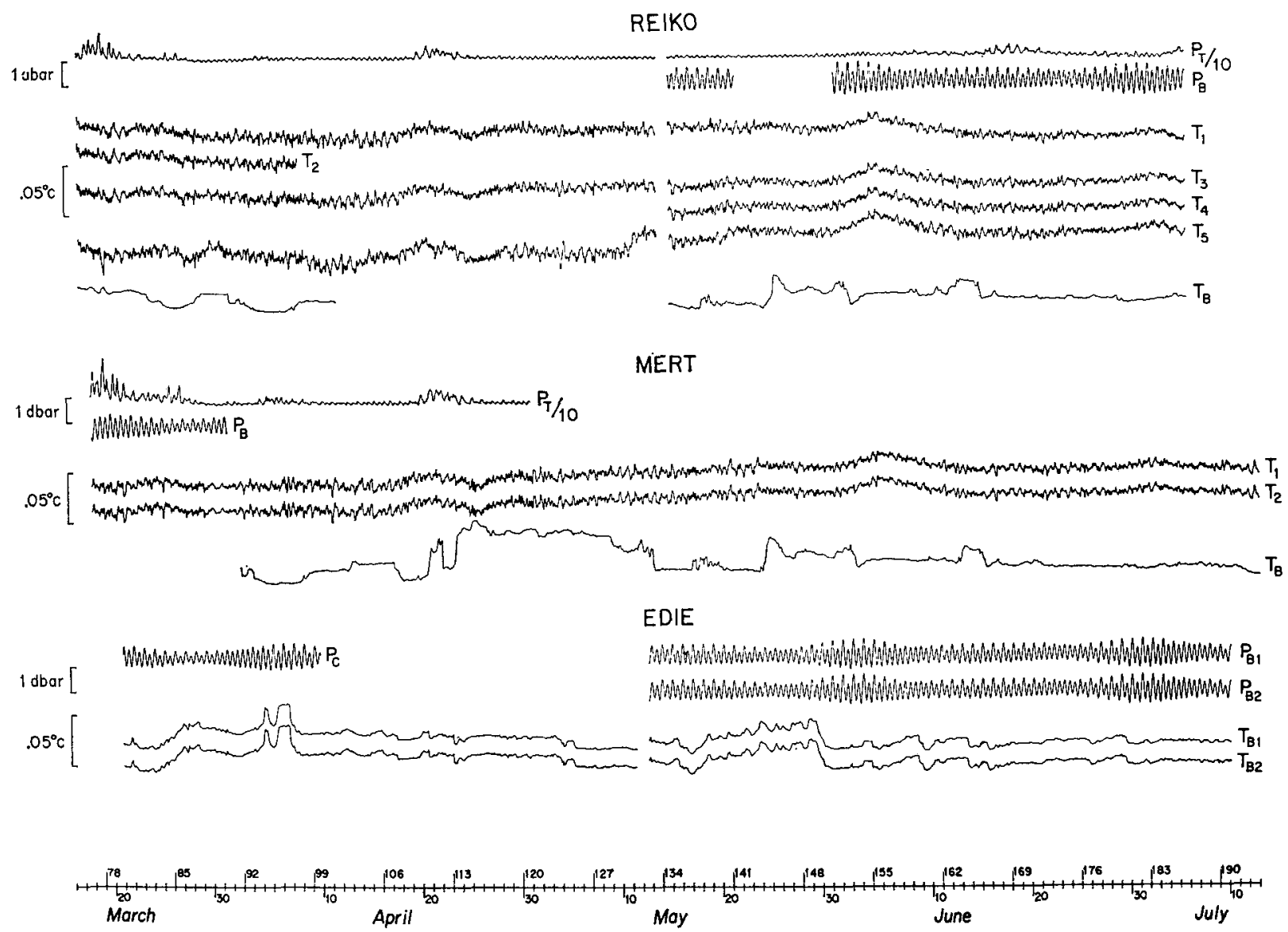

Fig. 7. Summary of 1973 pressure and temperature data in the MODE area. REIKO and MERT were located near the central mooring, with arrays similar to Fig.4 (Table 1); EDIE was located $180 \mathrm{~km}$ to the south, with all sensors $0.5 \mathrm{~m}$ above bottom. All temperatures are plotted on the same scale; pressure data at top of cable is compressed by a factor of 10 relative to bottom pressure data. Plotted data are 24 min averages of the measurements at $45 \mathrm{~s}$ intervals. The EDIE pressure data, $P_{C}$, is a composite record of $P_{B 1}$ and $P_{B 2}$, both of which were noisy. REIKO and EDIE were recovered and repaired in mid-May. Tick marks are at Greenwich midnight; year days are indicated.

sensors noisy from the beginning, and only 20 days of composite data $\left(P_{c}\right)$ could be recovered.

\section{Comments on Equipment FaIluRes}

Of the 18 sensors installed on the three capsules, nine developed trouble during the first half of the experiment. Of the nine failures, six were related to high-pressure cable connectors and splices. A factory defect in which the cable conductor pulled loose from the connector pin under high pressure was responsible for four failures. One connector accidentally disconnected during launch, and a defective splice made by our group accounted for two other cable-related failures.

The difficulty with the remaining three sensors was assumed to be related to lead-acid batteries that are exposed to seawater under high pressure. In one group of batteries, assembled in the field just prior to the cruise, tar used to seal the top of the battery did not adhere well to the cable insulation. Post-MODE tests indicated that water could seep along the battery lead to cause a high-resistance short to the sea. Since the negative side of the battery was connected to the sea through the grounded sensor case, discharge of the battery and noise in the sensor signal could result.

\section{In situ estimates of instrumental noise}

The remainder of the paper deals with instrumental noise spectra, estimated from duplicate instrumentation. These estimates are crucial when the very reality of the recorded signals is in doubt. They will provide guidance concerning the feasibility of proposed future experiments.

The central theme is the estimate of noise spectra, defined as the spectra of the output of instruments adequately sheltered from all inputs. Signals can be reliably observed within those frequency bands where the signal exceeds noise. The difficulty with laboratory measurements of noise is that the surface environment is much more variable than the benthic environment, so it is often hard to provide the required insulation. 


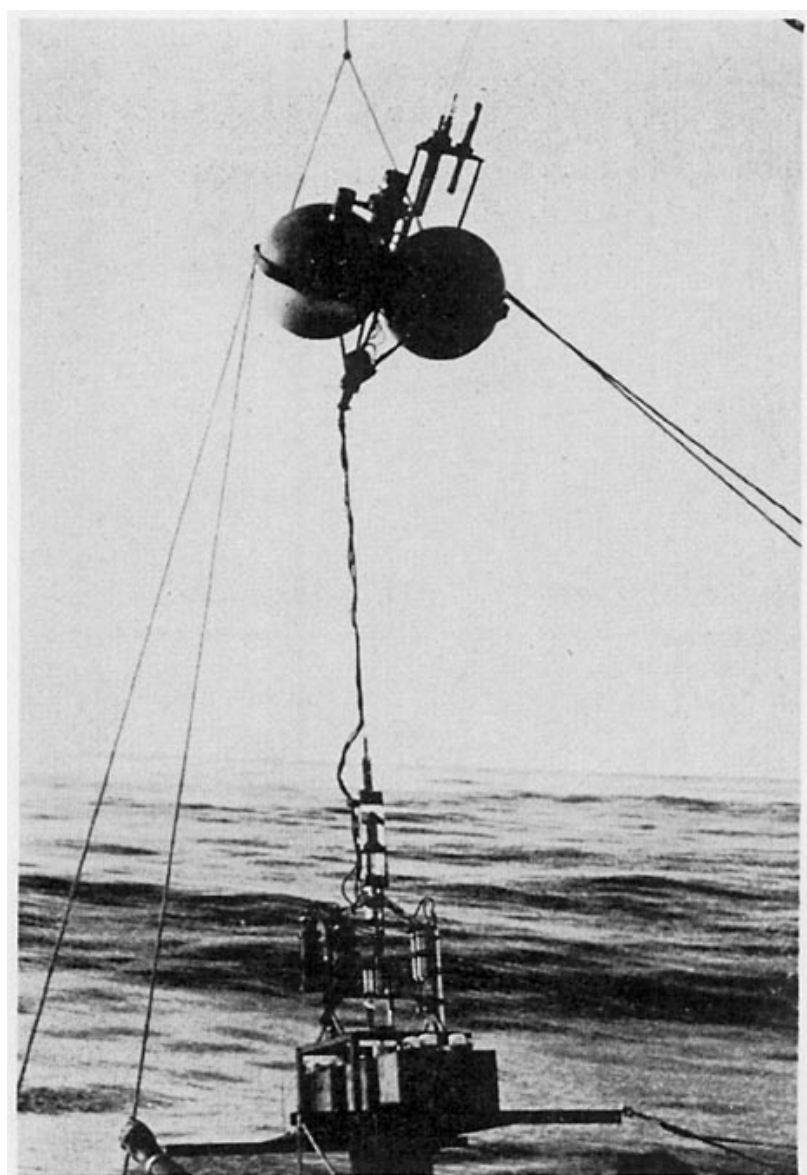

FIG. 8. Capsule EDIE about to be launched from the F. V. $H$ unt during the MODE experiment in March 1973. Two quartzcrystal temperature and two quartz-crystal pressure sensors are located on the instrument frame, which is attached to EDIE by a stainless steel cable. External lead-acid batteries, which are used to power the pressure sensors, are attached to the anchor frame. A release mechanism, which is activated by an acoustic command or a preset timer, allows the capsule and the instrument frame to separate from the anchor frame and to surface at the end of an experiment.

Further, there is a reasonable doubt whether instrument noise at atmospheric pressure is the same as that on the seafloor.

Noise estimates made in situ at the time and place of the experiment are therefore desirable. This is done by analyzing the difference, $x_{1}-x_{2}$, of duplicate instrumentation. If this difference is relatively small compared to $x$ (down $50 \mathrm{~dB}$ in some of our pressure measurements), then the in situ calibration needs to be known to great precision. Further, there must not be an appreciable source of noise common to both $x_{1}$ and $x_{2}$ that disappears from the difference $x_{1}-x_{2}$. This requirement for independence in duplicate instrumentation is crucial, and in our experience rarely convincingly demonstrated (e.g., we use duplicate transducers but a common power source and a common recording system).

In the following we shall raise some of the questions of multiple instrumentation and give some preliminary conclusions. Let

$$
x_{i}(t)=s(t)+n_{i}(t), \quad i=1,2,
$$

designate the output signal of the $i$ th transducer as a linear superposition of signal and noise. We presume $s, n_{1}$ and $n_{2}$ to be uncorrelated, i.e., $\left\langle s n_{i}\right\rangle=0,\left\langle n_{1} n_{2}\right\rangle=0$. Then

$$
\rho_{i j}(\tau)=\left\langle x_{i}(t) x_{j}(t-\tau)\right\rangle=\langle s(t) s(t-\tau)\rangle+\delta_{i j}\left\langle n_{i}(t) n_{j}(t-\tau)\right\rangle,
$$

$C_{i j}(\omega)=\int_{-\infty}^{+\infty} \rho_{i j}(\tau) e^{-i \omega \tau} d \tau=S(\omega)+\delta_{i j} N_{i j}(\omega)$,

with $\delta_{i j}=1$ for $i=j$ and zero otherwise. Thus

$$
\begin{gathered}
C_{i i}(\omega)=S(\omega)+N_{i i}(\omega), \quad C_{12}(\omega)=S(\omega), \quad(2),(3) \\
N(\omega) \equiv \frac{1}{2}\left[\left(N_{11}(\omega)+N_{22}(\omega)\right]\right. \\
=\frac{1}{2}\left[C_{11}(\omega)+C_{22}(\omega)\right]-C_{12}(\omega) . \quad(4)
\end{gathered}
$$

Proceeding as before, we find that the spectrum of the record difference $d(t)=x_{1}(t)-x_{2}(t)$ is given by

$$
D(\omega)=2 N(\omega) \text {. }
$$

For records of finite length the cross products $\left\langle s n_{i}\right\rangle$ and $\left\langle n_{i} n_{j}\right\rangle$ do not, of course, vanish as previously assumed: $\left\langle s n_{i}\right\rangle$ can couple energy from the spectrum into the noise estimate; thus, in the case of high signal-tonoise ratios the noise estimates become unreliable. The uncertainty of the spectral estimates can be estimated analytically, but we prefer to rely on a numerical experiment (Fig. 9), designed to resemble the MODE analysis in vital aspects. Three Gaussian white noise

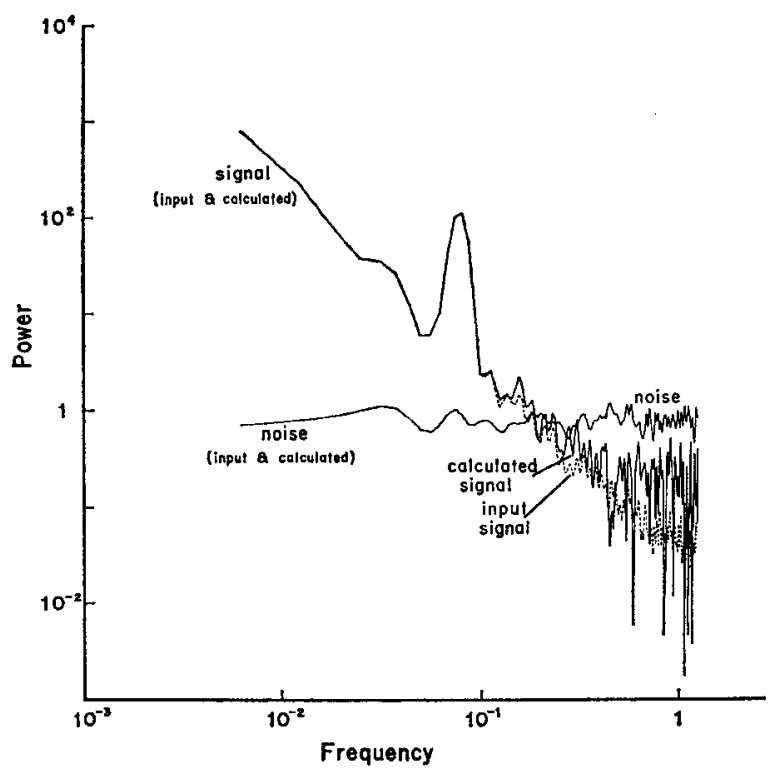

FIG. 9. Numerical noise experiment. The generated input signal spectrum (dashed) overlaps the calculated signal spectrum (solid) at low frequencies. Calculated and input noise spectra overlap at all frequencies. All units are arbitrary. 


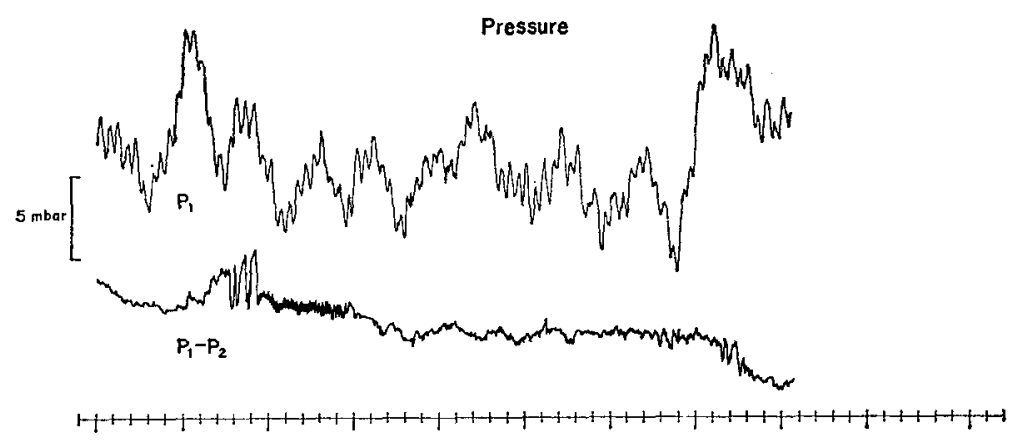

Temperafure

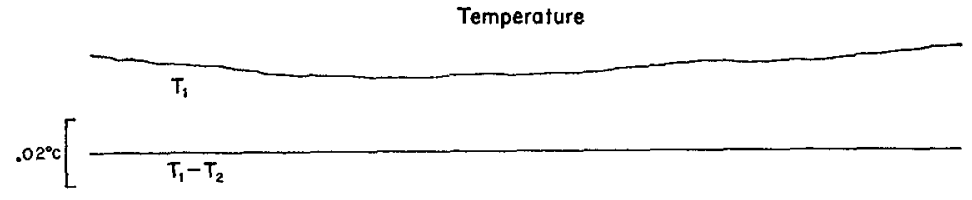

$$
10\left(T_{1}-T_{2}\right)
$$

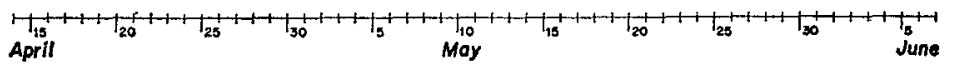

FIG. 10. Noise test conducted during 1972 in IGPP well (see also Fig. 3). Duplicate pressure and temperature records are compared to evaluate sensor noise and drift.

series were generated by a random number program. The first two are interpreted as $n_{1}(t)$ and $n_{2}(t)$. The third series was filtered to give a $\omega^{-2}$ spectrum characteristic of the geophysical time series, with a superimposed sinusoid to resemble a tide. We call this the input signal $s(t)$. The input signal spectrum $S(\omega)$ and input noise spectrum $N(\omega)=\frac{1}{2}\left(N_{11}+N_{22}\right)$ were obtained from spectral analysis of $s(t)$ and $\frac{1}{2}\left[n_{1}(t)+n_{2}(t)\right]$, respectively, taking care to prewhiten $s(t)$ prior to analysis and compensated subsequently. The input spectra are shown in Fig. 9.

We then produced two synthetic instrument records $x_{i}(t)=s(t)+n_{i}(t), i=1,2$, prewhitened as previously, and calculated the signal spectrum from (3) and the
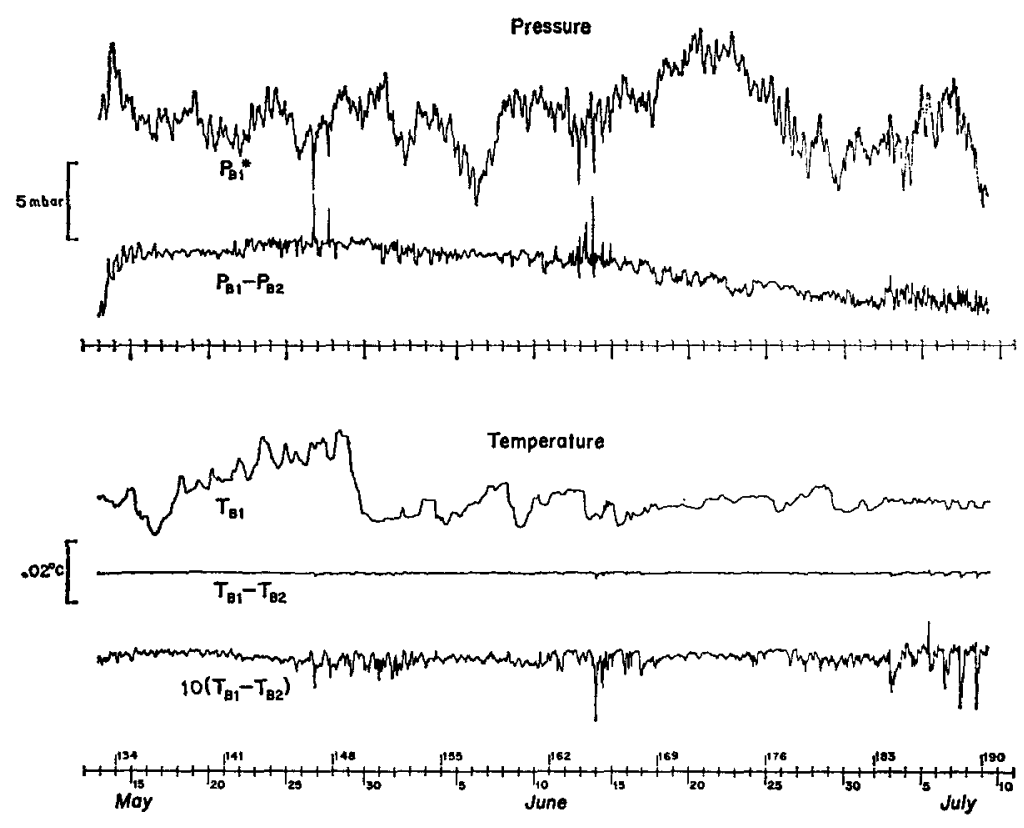

FIG. 11. Seafloor noise test conducted during 1973 in the MODE area using capsule EDIE. $P_{B 1}{ }^{*}$ is the "detided" bottom pressure ( $P_{B 1}$ minus predicted tide). 


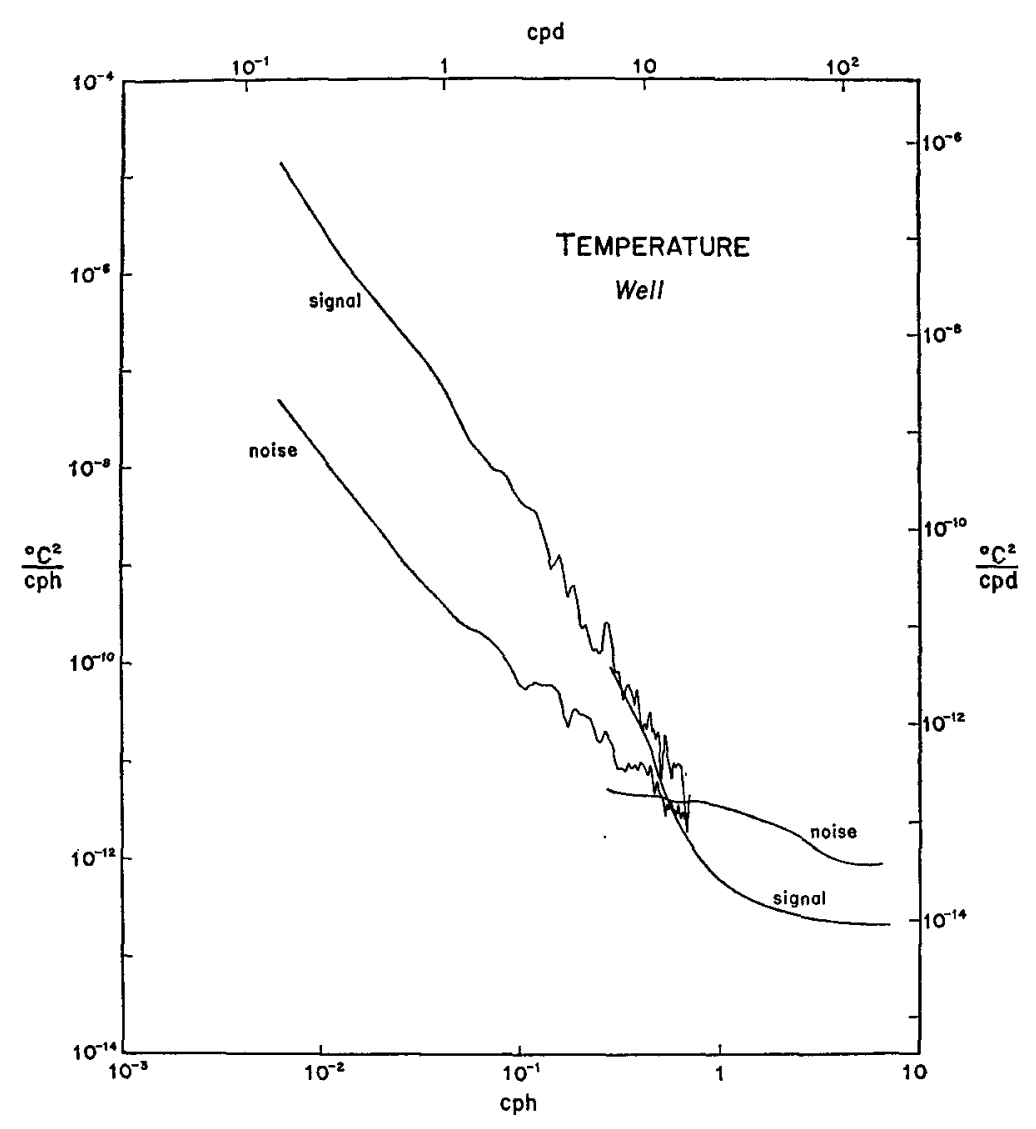

FIG. 12. Spectra of noise test performed in IGPP well, computed according to Eqs.

(3) and (5). Spectra at high frequencies have been smoothed.

noise spectrum $N(\omega)$ [Eqs. (4) and (5) lead to essentially identical results]. Input and calculated noise spectra agree and could not be separately plotted. Input and calculated signal spectra agree at low frequencies (where $S / N \gg 1$ ), but toward high frequencies the calculated signal spectrum shows increasing variability (aside from an apparent increase in the wiggliness of all spectra as a result of the logarithmic frequency scale). A bias which places the calculated above the input signal spectrum is due to some negative values of $C_{12}$ that cannot be plotted. In a somewhat analogous manner, the individual calculated (but not input) noise spectra $N_{11}$ and $N_{22}$ (not plotted) show increasing variability toward the low frequencies (where the noise is relatively low). This is particularly the case in the tidal band, thus giving the appearance of selective noisiness. It is for this reason that we prefer to use the average noise, $N=\frac{1}{2}\left(N_{11}+N_{22}\right)$, which does not have these features.

In summary, there is a large variance in the estimates of the calculated signal spectrum where the signal is low, and a larger variance in the estimates of the calculated noise spectra (but not of their sum) where the noise is low.
Calibrations are, of course, imperfectly known (though the error is less than $0.1 \%$ for the seafloor pressures), and we write ${ }^{4}$

$$
x_{i}(l)=a_{i} s(t)+n_{i}(t),
$$

in place of (1). Proceeding as previously,

$$
\begin{gathered}
C_{i i}(\omega)={a_{i}}^{2} S(\omega)+N_{i i}(\omega), \quad C_{12}(\omega)=a_{1} a_{2} S(\omega), \\
D(\omega)=2 N(\omega)+\left(a_{1}-a_{2}\right)^{2} S(\omega) .
\end{gathered}
$$

The last term in (8) represents a contribution from calibration error in the determination of $N$. Even if $a_{1}$ and $a_{2}$ are very nearly correct, the calibration error will still be dominant for sufficiently large $S / N$. Our procedure is to compute $D$ for various trial values in the relative calibration $a_{2} / a_{1}$, and to set $N=\frac{1}{2} D_{\min }$. This was done at some frequency (frequencies) where the energy is large, such as a tidal peak. The procedure is

${ }^{4}$ Here we regard $x$ and $n$ in hertz (say) and $s$ in millibars, and so $a$ has units $\mathrm{Hz} \mathrm{mb}$. The noise spectrum is accordingly in $\mathrm{Hz}^{2}$ per unit band. If we wish to display the noise spectrum in equivalent pressure units, then $N_{i i}\left(\mathrm{mb}^{2}\right.$ per unit band) $=a_{i}{ }^{2} N_{i i}$ ( $\mathrm{Hz}^{2}$ per unit band), and $N=\frac{1}{2}\left(a_{1}^{2} N_{11}+a_{2}^{2} N_{22}\right)$. 


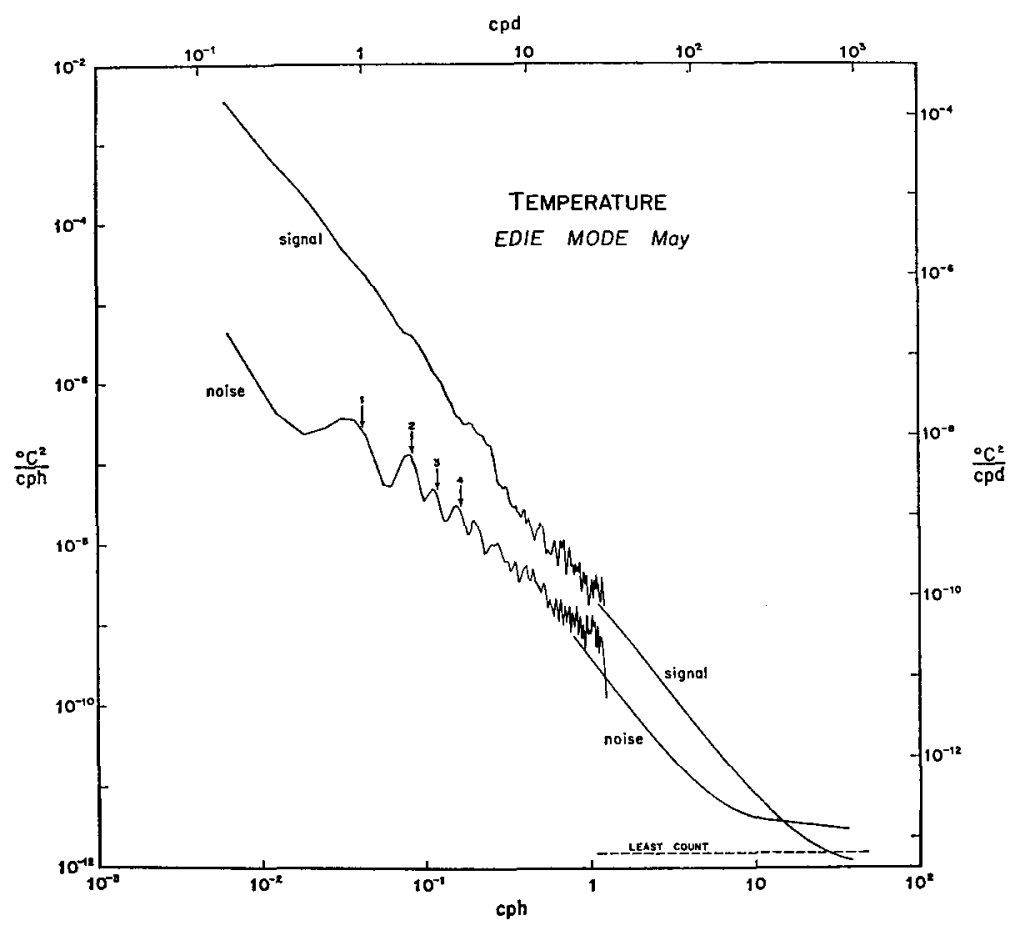

FIG. 13. Spectra of MODE bottom temperatures computed according to Eqs.

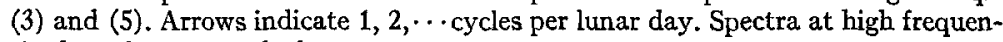
cies have been smoothed.

nothing more than to insist that the outputs of the instruments be equal for large calibration signals.

\section{Temperature sensor noise}

Figs. 10 and 11 show comparable plots of noise tests in the well and on MODE; corresponding spectra are in Figs. 12 and 13. In the well the temperature remained within $0.007^{\circ} \mathrm{C}$ throughout the test, yet the signal-tonoise ratio is large $(>20 \mathrm{~dB}$ below $1 \mathrm{cpd})$. On the Atlantic seafloor the temperature record is active, and the signal spectrum more than $20 \mathrm{~dB}$ above that in the well. Contrary to expectation, the noise spectrum is also $20 \mathrm{~dB}$ higher. Some, or perhaps all, of this increased noise level can be attributed to intermittent spikes in $T_{1}-T_{2}$. Transducers are very stable at low frequencies; the drift is less than $10^{-3}{ }^{\circ} \mathrm{C}$. At the highest frequency the MODE noise appears to be least-count limited at $\left(\delta T^{2} / 12\right) f_{N}=1.1 \times 10^{-12{ }^{\circ}} \mathrm{C}^{2}(\mathrm{cph})^{-1}$, where $\delta T=2.3 \times 10^{-5 \circ} \mathrm{C}$ is the least-count in the digital recording, and $f_{N}=40 \mathrm{cph}$ is the Nyquist frequency.

A puzzling feature is the tidal structure in the noise spectrum of MODE temperatures (Fig. 13). The peaks occur at multiples of the lunar frequencies. The crystal thermometers have pressure effects of the order $10^{-5}{ }^{\circ} \mathrm{C} \mathrm{dbar}{ }^{-1}$, which may vary by a factor of 2 between instruments. The semidiurnal tidal amplitude is 0.32 dbar, corresponding to an apparent temperature variation of $3 \times 10^{-6}{ }^{\circ} \mathrm{C}$, which is small compared to the measured noise peak of $5 \times 10^{-5 \circ} \mathrm{C}(\mathrm{rms})$. The coherence between $p(l)$ and $d(t)=T_{1}(t)-T_{2}(t)$ is found to be peaked at tidal frequencies, and equals $R=0.2$ for $M_{2}$. But the fractional contribution of pressure to the $d$ spectrum is $R^{2}$, so that again we find that the pressure contribution to tidal peaks in temperature noise is small, but not negligible.

The "hot-wire anemometer effect" offers a more plausible explanation. Electrical energy dissipated in a sensor raises its temperature slightly above ambient by an amount which varies inversely with the speed of the ventilating ocean current. Ventilation due to tidal flow leads to fluctuations at tidal frequencies in this temperature excess. A temperature difference can exist between two sensors due to differences in energy dissipation, and possibly from differences in flow caused by the supporting frame. The question is whether these differences can produce the observed peaks in the noise spectrum when the sensors are subject to the fluctuating tidal flow.

Maximum heating occurs when the ventilating current speed is zero. In a detailed analysis by Resch and Irish [(1972); their Eq. (8)], the temperature increase is given by

$$
\Delta T=c H^{0.8} D^{-1.4}
$$

where $H$ is the heat dissipated $(\mu \mathrm{W}), D$ the characteristic size of the sensor $(\mathrm{cm})$, and $c$ a constant dependent on fluid properties (and units). For the MODE tests 


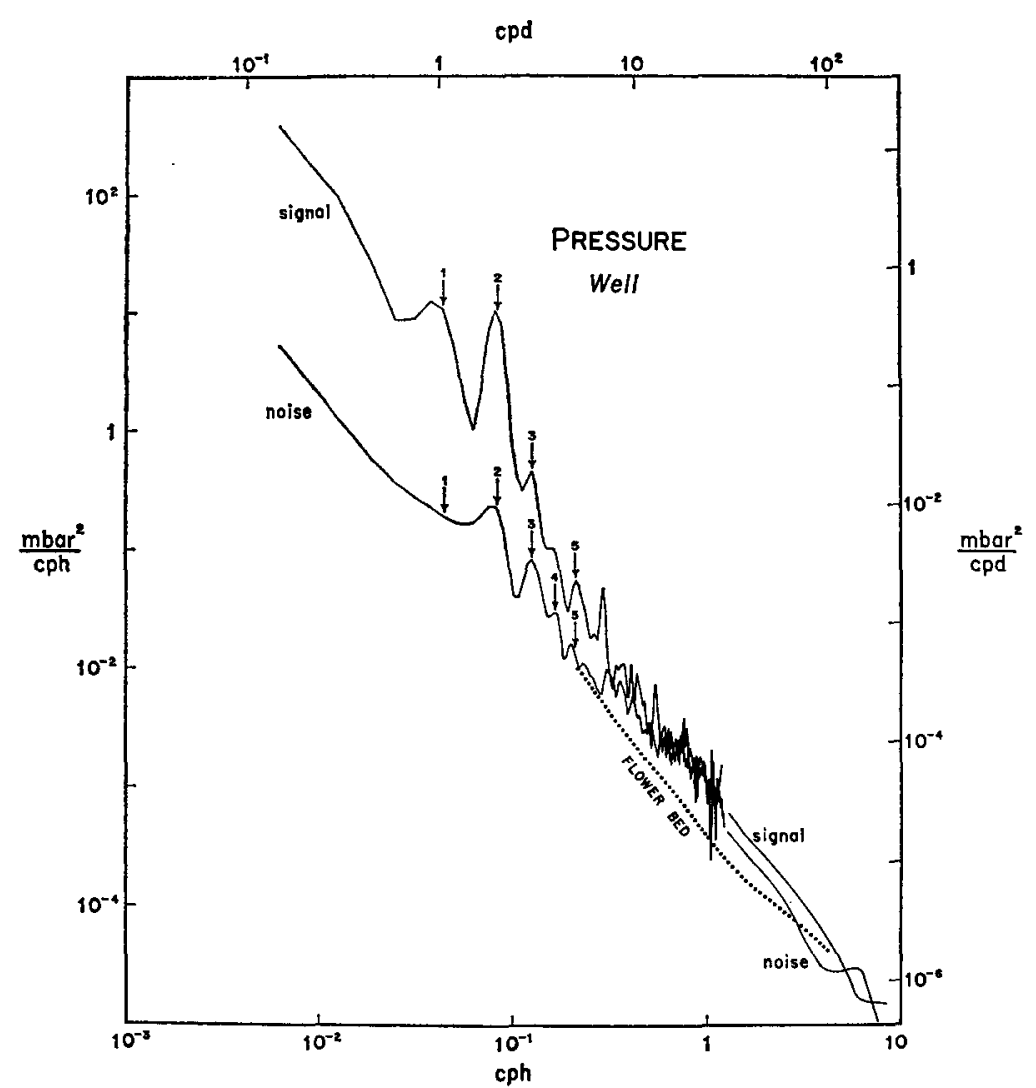

FIG. 14. Spectra of noise test performed in IGPP well computed according to Eqs. (3) and (5). Arrows indicate 1, 2, ... cycles per solar day. Dots indicate previous noise test of transducers buried $1.5 \mathrm{~m}$ in a flowerbed (Irish and Snodgrass, 1972). Spectra at high frequencies have been smoothed.

$c=1.16 \times 10^{-4}, H=100 \mu \mathrm{W}$ (individual crystals might range from 50 to $150 \mu \mathrm{W}$ ), and $D=1 \mathrm{~cm}$ (for the crystal housing thermally isolated by a thin tube from the electric housing). This gives $\Delta T=5 \times 10^{-3 \circ} \mathrm{C}$ for the temperature excess at zero current (free convection). For currents above $0.1 \mathrm{~cm} \mathrm{~s}^{-1}$ the cooling is dominated by forced convection, and

$$
\Delta T=k_{1} H D^{-\frac{1}{2} \eta^{-\frac{1}{2}}}, \quad v>0.1 \mathrm{~cm} \mathrm{~s}^{-1},
$$

where $k=6.4 \times 10^{-6}$ (Resch and Irish, 1972). The result is $\Delta T=2 \times 10^{-3}, 0.6 \times 10^{-3}{ }^{\circ} \mathrm{C}$ for $v=0.1,1 \mathrm{~cm} \mathrm{~s}^{-1}$. The conclusion is that the observed tidal peak $\left(5 \times 10^{-5^{\circ}} \mathrm{C}\right.$ rms) could be the result of transducer heating during intervals of minimum flow.

\section{Pressure sensor noise}

The 42-day Well record (Fig. 10) is dominated by the semidiurnal atmospheric tides and by weatherinduced pressure fluctuations. An unexplained activity in one of the pressure records (21-25 April) is responsible for large excursions in $p_{1}-p_{2}$. The pressure spectrum (Fig. 14) shows well-defined peaks at solar frequencies (appropriate to atmospheric tides) whose magnitudes are in accord with expected values. The corresponding peaks in the noise spectrum (down $15 \mathrm{~dB}$ ) are a mystery. Calibration errors are not the answer; the noise peaks could be only slightly reduced by adjusting the calibration constants in accordance with Eq. (8).

The MODE pressure records (Fig. 11) and the pressure spectra (Fig. 15) show very prominent tidal effects, as expected. When the predicted tides are subtracted, the residual records still show some conspicuous tidal peaks (but down by $40 \mathrm{~dB}$ for $M_{2}$ ). The residual peaks are believed to be associated with baroclinic tides that are not phase-locked to the tide-producing potential (Munk and Cartwright, 1966).

But the tidal peaks in the noise spectrum, though very small (down $50 \mathrm{~dB}$ for $M_{2}$ ), are again a puzzle. These peaks are now at lunar frequencies, but the general level is not unlike that in the well.

Referring to Fig. 11 we note that the difference pressure infers a sensor noise of about $1 \mathrm{mb}$. After an initial stabilizing time of 4 days, the relative drift varies from 1-3 mb per month. Above $10 \mathrm{cph}$ the spectra are leastcount limited at $\left(\delta p^{2} / 12\right) f_{N}=6.8 \times 10^{-5} \mathrm{mb}^{2}(\mathrm{cph})^{-1}$, where $\delta p=0.18 \mathrm{mb}$ is the least-count in the digital recording, and $f_{N}=40 \mathrm{cph}$ is the Nyquist frequency. 


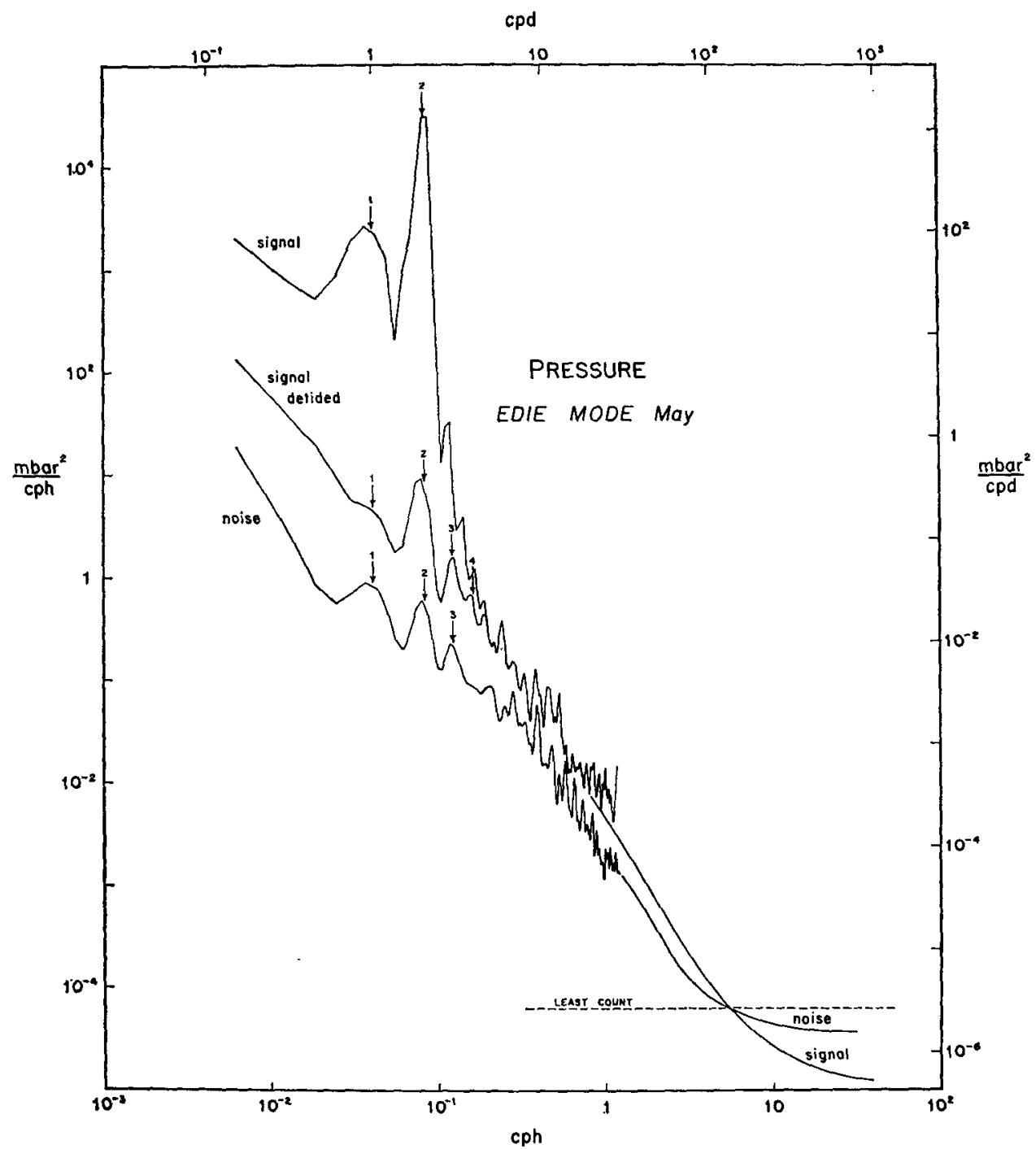

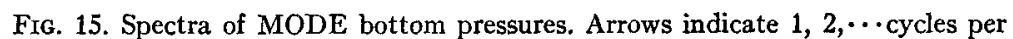
lunar day. Spectra at high frequencies have been smoothed.

We now explore several hypotheses concerning the tidal structure in the noise spectrum.

\section{a. Dynamic pressure}

A current of $5 \mathrm{~cm} \mathrm{~s}^{-1}$ is associated with a dynamic pressure $\rho v^{2}=25$ dyn $\mathrm{cm}^{-2}=0.025 \mathrm{mb}$. Depending on orientation, a fraction of this pressure is sensed by the crystal gauge, and it is conceivable that two gauges could experience a difference of $0.01 \mathrm{mb}$. The recorded $M_{2}$ peak corresponds to $0.2 \mathrm{mb}$ (rms).

\section{b. Sensor nonlinearity}

Differences in the nonlinearity of the sensors would produce different amplitudes in tidal harmonics and thus lead to tidal components in $p_{1}-p_{2}$. The sensor output frequency $f$ corresponding to a calibration pres- sure $p$ was least-square fitted to

$$
f=a+b p+c p^{2}+d p^{3} .
$$

Setting $p=p_{0}+\alpha \cos \omega t$ gives

$$
\begin{aligned}
f=f_{0}+\frac{c^{\prime} \alpha^{2}}{2}+\left(b^{\prime}+\frac{3 d^{\prime} \alpha^{2}}{4}\right) \alpha \cos \omega t \\
+\frac{c^{\prime} \alpha^{2}}{2} \cos 2 \omega t+\frac{d^{\prime} \alpha^{3}}{4} \cos 3 \omega t
\end{aligned}
$$

where $b^{\prime}=b+2 c p_{0}+3 d p_{0}{ }^{2}$ is the slope of the calibration curve at $p_{0}, c^{\prime}=c+3 d p_{0}$, and $d^{\prime}=d$. Solving the cubic equation (11) for $p(f)$ and substituting for $f$ from (12), we retrieve $p=p_{0}+\alpha \cos \omega t$. But for a linearized instrument response,

$$
f-f_{0}=b^{\prime}\left(p-p_{0}\right)
$$


and solving for $p-p_{0}$ with $f-f_{0}$ as given in (12), we find

$$
p-p_{0}=\alpha[\epsilon+(1+3 \zeta) \cos \omega t+\epsilon \cos 2 \omega t+\cdots]
$$

where

$$
\epsilon=\frac{\left(c+3 d p_{0}\right) \alpha}{2 b^{\prime}}, \quad \zeta=\frac{d \alpha^{2}}{4 b^{\prime}} .
$$

The nonlinearity introduces (i) a change in the "mean" pressure by $\alpha \epsilon$, (ii) a fractional change $3 \zeta$ in the response to the primary frequency, and (iii) higher harmonics of order $\alpha \epsilon$. For a typical sensor $a=2 \times 10^{3} \mathrm{~Hz}, b=12.1 \mathrm{~Hz}$ $\mathrm{dbar}^{-1}, c=3.5 \times 10^{-5} \mathrm{~Hz} \mathrm{dbar}^{-2}, d=10^{-10} \mathrm{~Hz} \mathrm{dbar}^{-3}$. With $p_{0}=5500 \mathrm{dbar}$ and $\alpha=0.3 \mathrm{dbar}$ to model the depth and tides of the MODE experiment, $\epsilon=4.5 \times 10^{-7}$ and $\zeta=1.9 \times 10^{-13}$. Assuming that differences in sensor nonlinearity are of the same order as the nonlinearity of individual sensors, the overall effects are negligible.

\section{c. Hot-wire anemometer effect}

The intermittent character of the spikes in the pressure difference record, and the related occurrence of spikes in the pressure and temperature difference records at tidal intervals leads one to suspect that "anemometer effects" are responsible. The appropriate geometry is that of a thin, long, vertical cylinder $(d=3 \mathrm{~cm}, l=45 \mathrm{~cm})$. The estimate for free convection would need to take into account interference with the flow along the sensor due to two large supporting clamps. For forced convection by flow perpendicular to a long cylinder, the temperature rise is proportional to the heat per unit length, i.e.,

$$
\Delta T=k_{2} d^{-\frac{1}{2} v^{-\frac{1}{2}}}(H / l) .
$$

For $H=0.28 \mathrm{~W}$ and the appropriate dimensions and constants, $\Delta T=0.074,0.023^{\circ} \mathrm{C}$ for $v=0.1,1 \mathrm{~cm} \mathrm{~s}^{-1}$. A typical temperature coefficient of the pressure transducers is $20 \mathrm{mb}^{\circ} \mathrm{C}^{-1}$, and so the equivalent pressure signals are $1.5,0.5 \mathrm{mb}$, respectively. The observed tidal peak in the noise spectrum of $0.2 \mathrm{mb}$ (rms) could conceivably be the result of an "anemometer effect," but one is hard put to account for occasional spikes of up to $5 \mathrm{mb}$.

\section{Comments on sensor noise}

There are two basic puzzles in our estimates of transducer noise: (i) a tidal line spectrum ${ }^{5}$ in $P_{1}-P_{2}$ and

$T_{1}-T_{2}$ and (ii) a $20 \mathrm{~dB}$ excess in the temperature noise continuum in the ocean "relative to the well. Computational effects, sensor calibrations," sensor nonlinearities, dynamic pressure and temperature cross talk have been eliminated as explanations for (i). Only the "hot-wire anemometer effect" can serve as a plausible explanation of the tidal line spectrum on the seafloor, but this leaves unexplained the solar tidal peaks in $P_{1}-P_{2}$ for the well test. We have no understanding of (ii). It is conceivable that we are seeing the effects of some type of signalconnected noise.

Acknowledgments. This work was supported by the Office of Naval Research (Contract N00014-69-A-02006008) and the National Science Foundation (Grant NSF-GX-29052).

This effect is very pronounced in some recent tidal measurements off Brest (Snodgrass and Wimbush, 1974).

\section{REFERENCES}

Baker, D. J., Jr., R. Wearn and W. Hill, 1973: Bottom pressure and temperature measurements in the MODE area. MODE Hot Line News, No. 28, 1.

Caldwell, D. R., F. E. Snodgrass and M. H. Wimbush, 1969; Sensors in the deep sea. Physics Today, 22, 34-42.

Irish, J. D., and F. E. Snodgrass, 1972: Quartz crystals as multipurpose oceanographic sensors-I. Pressure. Deep Sea Res., 19, $165-169$.

Munk, W. H., and D. E. Cartwright, 1966: Tidal spectroscopy and prediction. Phil. Trans. Roy. Soc. London, A259, 533-581.

Resch, F. J., and J. D. Irish, 1972: Quartz crystals as multipurpose oceanographic sensors-II. Speed. Deep Sea Res., 19, 171-178.

Snodgrass, F. E., 1968: Deep sea instrument capsule. Science, 162, 78-87.

- , and M. H. Wimbush, 1974: Evaluation of deep sea tide gauge sensors. Proc. IEEE Intern. Conf. Engineering in the Ocean Environment, Vol. 1, 350-353. 